\title{
Um Mundo Unificado: Cosmologia, Vida e Morte entre os Apinaje
}

Odair Giraldin Neste artigo pretendo apresentar informações e argumentos que possam mostrar como um mesmo princípio está presente tanto nos aspectos ligados aos problemas da vida, doença, cura, morte e vida post-mortem, quanto nas interpretações que os Apinaje fazem de seu cosmos. Neste sentido, entendo que os Apinaje fazem suas interpretações baseados no mesmo princípio de dualismo diametral e concêntrico. Para as questões relacionadas aos aspectos acima mencionados, entretanto, trata-se de um dualismo recursivo (cf. Seeger 1989), pois que concebem um gradiente entre os elementos do universo, sempre relacionados dois a dois, segundo o mesmo princípio valorativo de mais forte e mais fraco. Este gradiente relaciona também os elementos vegetais, animais e minerais. Há, entre estes elementos, um gradiente de valor. Os vegetais são considerados mais fortes que os animais, e estes mais fortes que os minerais.

\section{OS APINAJ E}

Localizados ao norte do Estado do Tocantins, na região conhecida como Bico do Papagaio, os Apinaje ocupam uma área de aproximadamente cento e quarenta mil hectares de terras demarcadas e homologadas, em sua maioria no município de Tocantinópolis. Com uma população de cerca de mil e cem pessoas, habitam oito aldeias. Quatro delas estão próximas às margens dos afluentes do Tocantins (aldeias Mariazinha, Riachinho, Bonito e Botica), todas 
As outras quatro estão localizadas na parte do território que demanda para o rio Araguaia (aldeias São J osé [antiga aldeia Bacaba], Patizal, Cocalinho e Buriti Grande [aldeia recémfundada]), todas elas estreitamente relacionadas à aldeia principal delas, São J osé.

Os Apinaje são um dos povos J ê Setentrionais² , falante de língua homônina. Em contato permanente com a sociedade circundante desde o início do século XIX, quando sua população foi estimada em quatro mil e duzentas pessoas, sofreram um processo de depopulação constante até a década de 1960, quando chegaram a apenas duzentas pessoas. Desde então, seguem a tendência de recuperação populacional verificada na maior parte dos grupos indígenas que habitam o Brasil. Eles foram visitados por diversos viajantes, como Castelnau na década de 1840 ([1844] 1949), mas a primeira monografia sobre eles foi escrita por Curt Nimuendaju quase um século depois (Nimuendaju [1939] 1983). Este trabalho do etnólogo alemão foi responsável pela projeção dos Apinaje no cenário antropológico acadêmico mundial, pela conhecida anomalia Apinaje de um tipo sui generis de troca matrimonial, supostamente realizada entre quatro grupos ${ }^{3}$.

Com pesquisas realizadas nas décadas de 1960 e 1970, Da Matta mostrou que não havia aquela anomalia, sendo a mesma fruto de uma incorreta interpretação de Nimuendaju do sistema de metades existente tanto entre os Apinaje como entre o Timbira Orientais. Para Da_Matta, os Apinaje possuem um dualismo que é tanto diametral quanto concêntrico. Num dos pares de metades (as metades Koti/Koré), a afiliação se dá através dos nomes pessoais e revela um princípio diametral. No outro par de metades (Ipôgnhotxwàin/Krénhotxwàin), cuja afialiação se daria pela transmissão de amizade formal, o princípio éo do dualismo concêntrico, sendo a primeira associada ao centro (pátio) e a segunda à periferia (às casas). Para Da_Matta, a concepção de mundo dos Apinaje, no entanto, seria baseada tanto no dualismo diametral quanto no concêntrico (Da Matta 1976:64-68).

Em minhas pesquisas entre os Apinaje atuais ${ }^{4}$, pude constatar que os principais elementos da sua cosmologia, descritos tanto por Nimuendaju quanto por Da Matta, continuam operantes entre os membros daquele povo. E através do entendimento desta cosmologia, classificada pelo dualismo recursivo (ao mesmo tempo diametral e concêntrico), pode-se melhor entender suas concepções dos seres que a compõem e das relações que se estabelecem entre eles. Como em outros grupos das terras baixas sulamericanas, estas relações são entre agentes possuidores de corpos diferentes, mas unificados através de um princípio comum: o espírito (ou alma). 


\section{O KARÕ E AS RELAÇÕES ENTRE MUNDO VEGETAL, ANIMAL E MINERAL}

Viveiros de Castro (1996:119) argumenta que, para a maioria das sociedades indígenas da América do Sul, a espiritualidade das plantas, meteoros e artefatos é secundária diante da espiritualidade dos animais. Estes últimos são o protótipo extra-humano do Outro. Mas ele chama a atenção (1996: nota 10) para algumas culturas da Amazônia Ocidental, particularmente aquelas que fazem uso de alucinógenos, nas quais a personificação das plantas parece ser tão importante quanto a dos animais.

Meu objetivo é apresentar informações que dão conta da importância de interpretações das cosmologias dos povos J ê. Veremos que, mesmo na Amazônia Oriental, em um grupo que não usa tradicionalmente alucinógenos, o mundo vegetal é tão personificado quanto o animal.

Estes novos dados etnográficos abrem novas possibilidades de interpretações das sociedades J ê. Tidas como exemplos de sociedades dialéticas (Maybury-Lewis 1979) - cuja ênfase estaria dada ao nível da estrutura social e suas derivações, como as disputas que ocorrem entre as facções políticas - ou como exemplo de sociedades que se estruturariam pelo controle de bens escassos - sobretudo a força de trabalho (os genros), via controle das filhas, através da regra de uxorilocalidade - , como argumenta Turner (1979), os povos J ê, e aqui me restringi apenas aos Apinaje, revelam também uma cosmologia rica de significados que os tornam muito próximos de outros grupos amazônicos.

Não se trata, então, de um povo que concebe o mundo exclusivamente dividido em pares de oposição, como poderíamos pensar a partir do título do livro clássico de Da_Matta sobre os Apinaje (1976). Os Apinaje são mais um grupo que pensa o universo unificado através do compartilhamento de elementos (os mẽ karõ) presentes tanto no reino animal quanto no vegetal. Tais elementos mostram que também para os Apinaje não se aplica aquela dicotomia clássica do pensamento das sociedades modernas, separando natureza e cultura.

Com base na inspiração dada tanto pelas idéias de Overing (a partir de material sobre os Piaroa) quanto pelas pesquisas de Descola (entre os Achuar), procuro interpretar a sociedade Apinaje a partir destes princípios cosmológicos formulados e utilizados por eles para explicar seu universo. Sigo de perto as proposições mais recentes de Viveiros de Castro (1996) e Descola (1988). Baseados nas etnografias existentes sobre os povos indígenas das terras baixas sulamericanas, os autores argumentam que estes povos concebem o universo não 
fazendo a distinção entre natureza e cultura, como aquela realizada pelo pensamento ocidental. Mas, enquanto para Descola os ameríndios não distinguiriam natureza e cultura (Descola 1988:27), para Viveiros de Castro a característica do pensamento ameríndio sobre o universo aponta para um "perspectivismo", ou seja, os dois termos (Natureza e Cultura) são relacionais: enquanto o corpo (Natureza) diferencia, o espírito (Cultura) é o que unifica (cf. Viveiros de Castro 1996:116). Os seres que povoam o universo são todos "culturais", pois são resultantes de um processo dinâmico que os transformou, a partir de um momento inicial em que não se diferenciavam, em corpos diferentes. Mas todos guardam relações de similaridade ao nível espiritual, o que permite a comunicabilidade entre eles. Para algumas sociedades, como os Achuar, a comunicação é tida como a principal característica desta unidade (Descola 1988: 27).

Meus argumentos, a seguir, tentam mostrar o universo Apinaje a partir das relações que se estabelecem entre humanos, animais e plantas, e como elas se tornam compreensíveis quando as relacionamos às noções de doença, cura, morte e vida post-mortem. À semelhança de outras sociedades amazônicas, ver-se-á que os Apinaje também concebem o universo como fechado, unificado, no qual todos os elementos estão interrelacionados, conforme os argumentos de Descola apresentados acima. Mas esta interrelação dos elementos segue o mesmo princípio do dualismo recursivo, conforme exposto anteriormente.

Em minha interpretação, os elementos da flora são considerados como sendo mais fortes que os elementos da fauna. É este princípio que permite, como veremos, a utilização exclusiva de plantas como remédios (kanê), sendo que sempre se procura utilizar, como remédio, aquelas plantas que tenham alguma analogia com a forma do agente agressor.

\section{OS MẼ KARÕ $\tilde{E}^{5}$}

Quase todas as coisas existentes empiricamente possuem karõ. As exceções são a terra (pyka) e a água (gô). O termo karõ (mẽ karõ, no plural) poderia ser traduzido por "espírito" ou "alma". Manuela Carneiro da Cunha (1978) chama-o de um duplo, uma imagem. Môjgô (Moisés), um ex-pahi (ex-chefe) da aldeia São J osé, que é também um wajaga (xamã) respeitado, glosa o termo karõ por sombra. E usa como explicação a evidência empírica percebida na própria projeção da sombra de um corpo. Segundo ele, o karõ é composto de duas partes ${ }^{6}$, uma mais 
forte e outra mais fraca ${ }^{7}$. Quando se olha atentamente para uma sombra, pode-se perceber que na fronteira entre ela e a luz que se projeta existe uma penumbra, que não é tão escura quanto a primeira, nem tão clara quanto a segunda. Para ele, esta é a evidência empírica da presença destas duas partes do karõ. A sombra mais escura revela o karõ mais forte, enquanto que a sombra da penumbra é a presença do karõ mais fraco.

Esta 'presença' do karõ foi notada por Nimuendajú em suas pesquisas entre os Apinaje na década de 1930. Segundo ele, as mulheres da aldeia Bacaba (das quais descende a atual aldeia São J osé) cuidavam de suas roças com muito carinho e um zelo maternal, chegando ao ponto de tratarem as plantas de suas roças como se fossem seus filhos, chamando-as pelo termo de parentesco correspondente a filho (Nimuendaju [1939] 1983:90).

Em minhas pesquisas, na década de 1990, com a população descendente dos habitantes da mesma aldeia visitada por Nimuendaju, também encontrei informações das mulheres tratando suas plantas como se fossem seus filhos. E a recíproca também é verdadeira. Segundo elas, as plantas das suas roças tratam-nas como mães, e aos seus maridos, como pais ${ }^{8}$. Por isso, quando vão preparar os terrenos da roças para plantar, cuidam de retirar todos os capins e gravetos para deixar o terreno limpo. É para ficar "como se fosse o terreiro da casa", dizem estas mulheres. Afinal, segundo seus argumentos, elas não poderiam plantar seus "filhos" num "terreiro" sujo 9 . Da mesma forma, uma roça mal cuidada, cuja dona deixa suas plantas "sufocadas" pelas ervas daninhas, é sempre objeto de reprovação. Neste caso, há sempre a possibilidade de as plantas externarem seus sofrimentos através dos cantos mẽ myr (veja adiante).

Para consumir as plantas da roça, as mulheres, a fim de evitar malefícios que pudessem ser causados pelos mẽ karõ das mesmas ${ }^{10}$, conversam com elas antes de iniciar o processo de colheita. No caso da colheita de mandioca, as mulheres cuidam para que nenhum tubérculo seja abandonado na roça, como também para que nenhuma rama fique jogada ao solo. Tratam de recolher todas as mandiocas para serem consumidas, enquanto recolhem todas as ramas e colocam-nas para secar ao sol. Posteriormente, elas serão queimadas. Afirmam que se uma rama ficar no chão e começar a brotar, o karõ da mandioca chorará o mẽ myr, no qual apontará as razões de seu sofrimento. Neste caso, pode denunciar o desleixo dos donos da roça.

A exemplo dos Achuar, descritos por Descola (1988), para os Apinaje também existe a comunicabilidade entre os mẽ karõ, sejam de animais, vegetais ou de seres não vivos. Segundo os Apinaje, os mẽ karõ de todos os seres existentes, em situações de sofrimento 
podem abandonar o corpo (animal, humano, vegetal ou ser não-vivo, como veremos a seguir) e expressar seu sofrimento na forma de um choro, chamado de mẽ myr. Estes choros são ouvidos pelo wajaga (xamã), que os ensina para algumas mulheres especialistas, chamadas de mẽ myr mãati nhõtxwàin, ${ }^{11}$ ou seja, aquelas que conhecem e executam os choros (mẽ myr). São aquelas mulheres que estão interessadas em aprender tais cantos e em preservá-los, executando-os em situações cerimoniais apropriadas, sobretudo durante situações de liminaridade, tais como nos velórios e nos rituais de entrega de enfeites pelo amigo formal ${ }^{12}$. Como estes choros, quando são executados, podem ser performados estando a pessoa que os executa em pé, são chamados de mẽ myr mãati (onde mãati = alto). Diferem assim do choro ritual chamado de mẽ myr mãapri (onde mãapri = baixo), executado com as pessoas agachadas.

Eis alguns exemplos de mẽ myr mãati aprendidos por wajaga. Informaram-me que Atorkrã (Romão) ouviu o choro do karõ de uma camionete D10, que estava há muito tempo parada por problemas mecânicos. Ele ouviu seu choro, no qual a camionete dizia que estava com saudades da estrada, entre outras coisas. Atorkrã (Romão), então, contou o mẽ myr mãati que ouviu para Grer (J úlia Laranja), Grerti (J úlia Corredor) e Irepxi (Maria Barbosa), as três mulheres consideradas mẽ myr mãati nhõtxwàin.

Outro exemplo é um mẽ myr mãati do arroz. Contaram que, há alguns anos, plantouse uma grande roça de arroz na aldeia Mariazinha. Por alguma razão, estava passando a época da colheita e o arroz estava começando a cair. Os Apinaje de Mariazinha chamaram os da aldeia São J osé para ajudá-los na colheita. Ao chegarem, um wajaga ouviu o choro do arroz que sofria por estar caindo. Contaram-me também o caso do mẽ myr de um pé de macaúba. Algumas de suas folhas haviam sido cortadas, deixando pingar gotas de sua seiva. Com o vento, as folhas restantes emitiam um som. As pessoas que passavam por ela, no caminho de uma fonte, contaram isto a um wajaga. Ele foi até lá e ouviu seu choro, contando depois para Gréri (J úlia Laranja).

Há um exemplo de um mẽ myr de uma pessoa que estava sofrendo muito. Trata-se de uma mulher da aldeia Mariazinha que estava apanhando de seu marido. Um wajaga encontrou seu karõ sentado sobre um tronco de árvore, chorando. Neste choro, relatava seu sofrimento. 0 wajaga conseguiu convencer o karõ a voltar para o corpo, evitando, assim, a morte da mulher.

Mas há o exemplo de um mẽ myr de uma mulher que o emitiu antes de falecer, o que é considerado um fato inédito. Seu nome era Amdxàk (Orlanda), filha de minha nominadora 
Irepxi (Maria Barbosa) e casada com Kambot (Sebastião). No dia anterior à sua morte, no leito hospitalar, ela verbalizou seu mẽ myr, que foi ouvido pelos presentes (Irepxi, Grer (J úlia Laranja), Sikoi [irmã de Amdxàk] e Waxm ẽ [meio-irmão de Amdxàk]). Ao mesmo tempo, Romão ouviu-o na aldeia São J osé e o transmitiu a Grerti ( úlia Corredor). Através do mẽ myr, o karõ de Amdxàk (Orlanda) contava como ele foi aprisionado por Kambot (Sebastião) e dado por ele a um sapo, que o colocou no fundo de um lago. Ouvi também o caso de um karõ de uma criança que estava sendo maltratada pelo pai. Um wajaga ouviu e contou para Grer ( úlia Laranja).

Além destes, gravei diversos outros mẽ myr com Grerti (J úlia Corredor), como o de uma espingarda que estava sendo carregada à bandoleira num sol causticante; de uma menina que foi entregue pelo pai para um marido muito mais velho; de uma criança cujo karõ foi carregado por uma anta porque sua mãe aplicou-lhe gordura deste animal em seus cabelos; de um pé de bacuri, nominado pelos portadores do nome Kunuka e que, após secar, morreu.

\section{A DOENÇA}

A causa de uma doença pode ser interpretada de duas formas ${ }^{13}$ : ela tanto pode ser resultado da ação material de algum agente nocivo quanto da ação de algum karõ. No primeiro caso temos os exemplos das verminoses, que são muito comuns, ou de ferimentos provocados por algum instrumento, como cortes de machado, foice, faca, ou pancadas por queda de árvore ou por um tombo. Nestes casos, recorre-se a remédios (kanê) que são prescritos levando-se em consideração seu efeito terapêutico pelas qualidades farmacopéicas conhecidas pelos Apinaje. Para a cicatrização de ferimentos, por exemplo, utiliza-se a casca de cajueiro ou de uma outra árvore conhecida como cachamorra. Além desses, fazem uso constante de remédios ocidentais, fornecidos pelas enfermeiras na farmácia da aldeia.

Mas as doenças podem ser causadas, principalmente, pela ação dos mẽ karõ. Estes podem atacar o corpo de alguém após, por exemplo, a ingestão da parte material corpórea do agente. Ao comer determinado alimento, tanto animal quanto vegetal, a pessoa pode ser 'contaminada' pelo karõ do alimento, adoecendo ${ }^{14}$. Para combater a ação dos mẽ karõ, os Apinaje se utilizam de algum elemento de contra-ação, através de algum kanê ${ }^{15}$, que visa neutralizar a ação do karõ maléfico. Estes kanê provêm (como se verá adiante), quase 
exclusivamente, do reino vegetal.

Os Apinaje, a exemplo de outras sociedades amazônicas, também fazem uso de uma estratégia semântica como prevenção contra as ações dos mẽ karõ. Trata-se de uma tentativa de burlar o karõ, sobretudo o das caças, evitando-se utilizar os nomes próprios dos animais abatidos. Assim, os A pinaje classificam as caças que andam pelo termo Mry (inclui-se aqui a ema). J á para as caças que voam, mas que são maiores que um gavião, o termo utilizado é Àkti (inclui-se aqui a seriema). Os pássaros menores são chamados de Kuwênh ${ }^{16}$. Dizem os informantes Apinaje mais velhos que até um passado recente, quando um caçador trazia uma caça qualquer (por exemplo, um veado = Karà), ele jamais dizia o nome próprio da caça abatida. Referia-se sempre a ela como Mry. Se fosse uma caça que voa, chamava-a apenas deÀkti. Esta estratégia semântica, dizem, era para evitar que o karõ da caça abatida descobrisse onde estava sua parte corpórea, material, e atacasse quem a estava consumindo.

Existia, entre os Apinaje, uma forma de encantamento muito parecida com os anent dos Achuar (Descola 1988:321; 1998:27). Entre os Achuar, os anent são cantos que fazem parte das habilidades individuais dos caçadores. Com os anent, podem comunicar-se com os chefes das caças e convencê-los a se apresentar ao caçador. Entre os Apinaje, os cantos de encantamento são chamados de mẽ amnhi (onde mẽ = coletivo; amnhi = reflexivo) e eram aprendidos na cerimônia de iniciação masculina chamada de Pẽp kaàk. Os Apinaje mais antigos explicam-no como sendo um canto através do qual os humanos ${ }^{17}$ podem encantar e dominar, não os mẽ karõ de animais ou plantas, mas os próprios animais ou plantas. Vejamos alguns exemplos.

Há o mẽ amnhi da bacaba (uma espécie de palmeira de cujos frutos se extrai um suco). Dizem que, no passado, quando se descobria o primeiro cacho de bacaba maduro, os Pẽ $p$ (homens maduros que passaram pela cerimônia de iniciação de Pẽp kaàk) eram logo avisados. Alguém colhia a primeira bacaba e a conduzia até o pátio. Em torno dela, os Pẽp cantavam o mẽ amnhi ${ }^{18}$. Ao terminar, a bacaba era preparada e os velhos a consumiam. Após este ritual, toda bacaba encontrada podia ser consumida por todos, sem preocupação.

O mẽ amnhi da anta era realizado pelos Pẽp, sempre que uma delas era caçada. As pessoas repartiam a carne da anta no lugar onde foi abatida, colocando suas porções em cestos. Voltavam para a aldeia, indo na frente alguém com a cabeça da anta. Durante todo o percurso, os Pẽp cantavam o mẽ amnhi. Chegando na aldeia, cantavam novamente. Em 
seguida, a cabeça era moqueada e consumida apenas pelos velhos ${ }^{19}$.

O mẽ amnhi do formigão preto (mrumti) era também realizado pelos Pẽp e tinha efeito terapêutico. Quando de uma picada de formigão, considerada muito dolorida, o Pẽp cantava o mẽ amnhi do mrumti. Com este canto, o Pẽp conseguia retirar toda a dor provocada pela picada $^{20}$. Neste caso, o mẽ amnhi é considerado como um tipo de kanê.

Mas uma doença pode ser ocorrência da ação de feitiço (mẽ õxi) feito por um wajaga. Este consegue controlar o karõ de algum animal e enviá-lo para que ataque o corpo da pessoa. Neste caso, faz-se necessária a ação de outro wajaga, que consegue descobrir que karõ está atacando aquela pessoa e também quem o está enviando. A cura não se dará através da utilização de kanê, mas das ações do wajaga, que consegue retirar o feitiço do corpo do doente. Como primeiro passo para evitar novos ataques do feiticeiro, o wajaga deverá comunicar ao malfeitor para que ele pare de atacar a pessoa doente. Em caso de persistência, a solução mais radical reside na condenação e morte do feiticeiro. Há muitos anos que não se tem mais a morte de acusados de feitiçaria, sendo uma das últimas execuções ocorrida na década de trinta (Nimuendaju [1939] 1983:131-132). Uma acusação de feitiçaria, porém, é motivo para a saída de alguém de uma aldeia, mudando-se para outra.

\section{A CURA}

A lógica Apinaje para a cura está ligada à sua lógica da interpretação do mundo material como consistindo de matérias que possuem um duplo, uma imagem, um karõ. Para contrapor-se à ação de um karõ que ataca o corpo de alguém, recorre-se à ação de um princípio oposto, e mais potente, que possa neutralizá-lo. Este princípio é o kanê. Este é originário, quase exclusivamente, do reino vegetal ${ }^{21}$. Para todo tipo de indisposição física, encontra-se entre os vegetais um kanê. Um kanê será sempre uma planta que guarde algum traço de similaridade metonímica com o agente provocador da doença. Como Nimuendaju já o afirmou ([1939] 1983:111), o kanê para combater o karõ do karà (veado) é uma planta cujas folhas se assemelham aos chifres do veado. $O$ aroj-kanê é uma planta cuja caule se assemelha a um pé de arroz. A kãn-kanê (kãn = cana) é uma planta que lembra a cana-de-açúcar. Esta última é utilizada para combater os males provocados pelo consumo excessivo da cachaça. 
Como vimos, os cantos mẽ amnhi cumprem também funções curativas, através do poder que possuem para neutralizar a agressão que o agente está provocando no corpo da pessoa ${ }^{22}$. Existe uma dedicação constante das pessoas para ensinar aos mais jovens a utilização dos diversos tipos de remédios kanê. Dessa maneira, toda pessoa desde jovem sabe reconhecer quais as plantas que servem para cada tipo de enfermidade. Este conhecimento, entretanto, não impede uma certa especialização entre os Apinaje. Existem pessoas que são especialistas em determinados remédios, associados a determinados animais, ou então são considerados especialistas em certas enfermidades por terem adquirido este poder de determinado espírito. Conheci um homem, Nhinô (J oão), que é considerado capaz de curar ossos quebrados, além de problemas relacionados a contusões em geral. Afirma-se que ele adquiriu esta capacidade com o espírito do bicho-preguiça, pois uma vez ele conseguiu curar um filhote deste animal que estava com uma pata quebrada. Este homem não prescreve nenhum medicamento, apenas toca ou massageia o local ferido. Outro homem, Grékrw (J airo), é considerado especialista em remédio do tatu. Quando se detecta que o espírito deste animal está atacando o corpo de alguém, pede-se a ele que busque o remédio que é aplicado no corpo da pessoa23.

Os dados acima nos mostraram, então, que também na concepção de doença e cura está presente o princípio dualístico, mas com um viés hierarquizante. A busca nos elementos do mundo vegetal dos remédios para seus malefícios, utilizados como kanê, pode ser interpretada como uma consideração de que tais elementos são mais potentes e, por isso, podem se contrapor à ação maléfica que agride o corpo. Mas ocorre, obviamente, de as pessoas falecerem, mesmo com a ação dos kanê.

\section{A MORTE E A VIDA POST-MORTEM}

A morte é interpretada como o abandono prolongado e definitivo do karõ, que deixa o corpo da pessoa. Este pode sair do corpo, por exemplo, enquanto dormimos ou, como veremos adiante, quando nos encontramos em estado de sofrimento. Cabe ao wajaga providenciar para que o karõ retorne e ocupe novamente o corpo. Quando ocorre, entretanto, de o karõ abandonar o corpo por muito tempo, este fica fragilizado, podendo sofrer a ação de outros mẽ karõ e, neste caso, o corpo não resiste e morre ${ }^{24}$. 
Após o corpo morrer, o karõ, composto como vimos por duas partes, fica durante algum tempo nas proximidades do local onde a pessoa vivia. Assim que se encerra o luto, com a realização de 'festas' desejadas pelo falecido ou solicitadas pelos arranjadores de nomes (as cerimônias de mẽ ôkréporundi e/ou Pàrkapê [cf. Giraldin 2000]), o karõ vai morar definitivamente na aldeia dos mortos. Para os Apinaje, no mundo dos mẽ karõ existe tudo como neste mundo que vivemos, com a diferença que nós não podemos vê-lo ${ }^{25}$. Ali os mẽ karõ vivem em aldeias, comem, bebem, namoram, casam, têm relações sexuais e... morrem.

Esta morte do karõ é, na verdade, a morte daquela parte mais forte (ou mais escura da sombra) do karõ. Resta, ainda, a parte mais fraca dele. Esta sombra mais fraca (a alma do karõ), com a morte do karõ, pode se transformar, transmigrando para o mundo visível e tomando algumas formas diferentes. Pode se transformar num toco (um tronco de uma árvore morta), num cupim (aquela casa de terra construídas pelas térmites) ou ainda em uma caça, um Mry ${ }^{26}$. Quando o toco se desmancha pela ação do tempo, transforma-se em terra (pyka) e o karõ que o ocupava morre definitivamente pois, como vimos, a terra não possui karõ. Quando o cupim (casa das térmites) se desmancha e vira terra, o karõ também morre.

E quanto à caça? O desdobramento que me ocorreu foi pensar que as caças são portadoras de karõ de pessoas que já tivessem vivido uma existência humana. Eu coloquei esta indagação aos Apinaje. Perguntei-Ihes: "então, quando matamos uma caça, estamos potencialmente matando (e consumindo) um karõ de al gum panhi (termo glosado como pessoa) que faleceu?" A resposta foi negativa. Há formas de distinguir uma caça quando ela é o karõ de alguma pessoa falecida. Segundo os Apinaje, uma caça idealmente deve estar sempre gorda. Mas quando a caça é um karõ, ela é muito magra. Entretanto, quando uma caça está gorda, mas apresenta a carne escura, de coloração 'azulada', este é um sinal, segundo eles, de que se trata de um karõ, sendo imediatamente descartada ${ }^{27}$. Quando esta caça que é karõ morre, seu corpo se dissolve e mistura-se com a terra, e o karõ também morre. Desta vez, no entanto, morre definitivamente.

Questionei várias vezes os A pinaje para tentar descobrir sua interpretação para a seguinte questão: dado que os mẽ karõ morrem, como é que eles nascem? A maioria dos meus entrevistados não soube dar uma interpretação para o 'nascimento' do karõ. Para Môjgô (Moisés), que é um wajaga respeitado na aldeia São J osé, o karõ surge junto com a criança dentro do ventre materno ${ }^{28}$. 
Minha interpretação é que há um gradiente entre o reino vegetal, o reino animal e o reino mineral, havendo uma espécie de ciclo entre eles. Uma vez que tanto as plantas quanto os animais possuem karõ, acredito que exista entre eles uma relação de potencialidade, dada pela semelhança simpática, mas em que está presente o princípio do dualismo hierárquico. Ao nível vegetal e animal, os mẽkarõ estão em relação de similaridade, mas seus poderes não são igualados. A contrário, o vegetal é considerado mais forte. Por isso, por haver uma superioridade de poder contido nos mẽ karõ dos vegetais sobre os animais, é que estes últimos são utilizados como específicos para combater os malefícios provocados pelos mẽ karõ dos animais. Mas o karõ enfraquece e morre, sendo sua parte material transformada, passando, num processo de reciclagem, para o reino mineral. E do reino mineral nasce o reino vegetal e, deles, os mẽ karõ.

O fato de haver a plena potencialidade dos mẽ karõ nos animais, homens e caças, pode ser interpretada pela origem dos Apinaje a partir do reino vegetal. A humanidade, para os Apinaje, foi formada pela transformação de um vegetal, a cabaça (bottle gourds), ou gôkôn (gô = água). No mito de criação, Sol e Lua formam uma roça de cabaças. Depois de maduras, eles levam as cabaças para um rio e as lançam dentro d'água. Delas emergem os Apinaje (Nimuendaju [1939] 1983: 164; Giraldin 2000).

Na minha interpretação, esta é a razão de ser do reino vegetal, que origina os kanê. Para mim, não se trata apenas de uma utilização do princípio farmacopéico, mas desta interpretação cosmológica Apinaje, de que se trata da utilização da ação de um karõ de maior potência (do reino vegetal) para combater outro karõ, do reino animal ou do reino vegetal.

Odair Giraldin égraduado em História, mestre em Antropologia Social e doutor em Ciências Sociaispela Unicamp. É professor da Fundação Universidade do Tocantins (Unitins), lecionando no Campus de Porto Nacional. Em 1997, publicou Cayapó e Panara. Luta e Sobrevivência de um Povo Jê no Brasil Central, pelaEditora da Unicamp. 


\section{NOTAS}

1 Adotei a grafia Apinaje (com j, além da vogal final não acentuada), porque esta é a grafia utilizada pelos Apinaje atuais. $\mathrm{O} y$, usualmente encontrado na grafia no nome daquele povo, possui o som de 'i' ou ' $u$ '. A última vogal, se acentuada, teria o som de 'e' e não de 'é'.

2 Os Apinaje são também classificados lingüisticamente como Timbira Ocidental, para diferenciá-los dos Timbira Orientais (Krikati, Apanyekrá-Canela, Ramkokamekra-Canela, Krahô, Pukobye, Parakateye). Os demais povos J ê Setentrionais são os Suyá, os Mê bengôkré (Kayapó) e os Xikrin (Kayapó).

3 Para maiores informações sobre esta questão, confira DaMatta (1976).

4 Pesquisa para meu doutoramento, realizada entre 1996 e 1998, completando sete meses de campo. Neste período visitei todas a aldeias então existentes, tendo como base a aldeia São J osé.

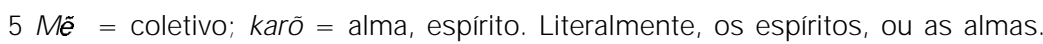

6 Segundo Carneiro da Cunha (1978:115), os Krahô afirmam que os mẽ karõ possuem quatro partes.

7 Note-se aqui o princípio do dualismo diametral e hierárquico, pois são dois karõ, um forte e outro fraco.

8 Os mê karõ, em suas manifestações lingüísticas, utilizam os termos Xyri (para pai) e Nhiri (para mãe).

9 Descola (1988:283) apresenta dados muito semelhantes para os Achuar. Segundo ele, a relação das mulheres Achuar com as plantas na roça é semelhante à da mãe com seus filhos, comunicando-se com elas da mesma maneira como trata com seus filhos. Cada mulher possui cantos (anent) com os quais procura se comunicar com as plantas, assim como se utiliza de amuletos (nantar) para protegê-las e fornecer boas colheitas.

10 Para os Xikrin, segundo Giannini (1991:83), as plantas não possuem karõ. Elas possuem, entretanto, uma substância que os Xikrin chamam de udju. É o udju que tem poderes curativos (1991:169).

11 nhõtxwàin é um sufixo que designa aquele(s) que faz(em) ou possui(em) algo (como gré nhõtxwàin = o cantador, pois gré é o verbo cantar; ainda mry nhõtxwàin = caçador ou caçadores, pois mryé tanto o substantivo caça quanto o verbo caçar). Também se utiliza nhõtxwàin para se referir às pessoas de um lugar: Patizal nhõtxwàin = os moradores da aldeia Patizal.

12 Desenvolvi este ponto em minha tese de doutorado (Giraldin 2000).

13 Giannini afirma que os Xikrin classificam as doenças em dois tipos. A doença cujo agente agressor é um animal ou as almas dos mortos (mekaron) é chamada de kane. Já a doença cujo agente é um feitiço é chamada de tãtã. Mas o agente causador da doença provocada por animal é sempre a alma, contaminando através do sangue ou roubando a "energia vital" (kadjuo) da pessoa. A doença tãtã é provocada por feitiço, tanto por um feiticeiro quanto pelos "donos controladores" dos animais que podem soprar feitiço na carne do animal e contaminar quem a consumir.

14 Nimuendaju ([1939] 1983:111) afirma também que uma pessoa pode adoecer comendo alimentos vegetais ou animais, e sendo contaminado pelo karõ. Pelas informações de Giannini (1991:82), as plantas das roças não causam doenças.

15 É interessante notar a variação semântica entre os termos Xikrin e Apinaje para doença e remédio. Segundo Giannini (1991:161) a doença que é causada por uma substância é chamada pelos Xikrin de kane, enquanto a doença provocada por feitiçaria é tatã. Os Xikrin chamam o remédio de pidjà, enquanto que os Apinaje o chamam de kanê.

16 Sobre uma classificação da avifauna entre os Xikrin, veja-se Giannini (1991). Ela não utiliza o termo kuven para referir-se aos pássaros menores, mas esta terminologia é encontrada em Bamberger (1967) para os Mê bengokre. Para os pássaros menores, ela grafou kwene. Para os pássaros da savana: kwenti.

17 Muito embora algumas mulheres os aprendessem, elas não os executavam. Algumas mulheres que atualmente sabem algum mẽ amnhi se recusam a cantá-los, exceto quando instigadas pelo antropólogo. Mas sempre dizem que não os sabem completamente. 
180 mẽ amnhi Apinaje parece corresponder ao canto Ben dos Mẽ bengokre-Kayapó. Segundo Lea (1986:246), o Ben é a voz do chefe que "representa a aldeia falando para si mesma".

19 Além destes, ouvi também outros relacionados à saída para uma caçada; outro para controlar os efeitos das tempestades e outros para os filhotes das caças. Mas este canto está caindo em desuso e, pior, está se perdendo, pois eles eram ensinados durante o período de reclusão dos jovens iniciandos, na cerimônia de Pêp kaàk. Esta cerimônia não acontece há muitos anos. Como não mais realizam as cerimônias e os últimos velhos que passaram pela iniciação estão na fase final da vida, os Apinaje dizem que os mẽ amnhi estão se perdendo: Na pikunor kumrê $x$ = sumiu para sempre ( $p i=$ ênfase, duplamente; Akunok = desaparecer, sumir; kumrê $x=$ advérbio de intensidade).

20 Segundo Giannini (1991:168), os Xikrin também possuem algum tipo de encantamento que tem função terapêutica. Mas ela não os trabalhou. Estes mẽ amnhi Apinaje são semelhantes também ao canto Suyá ao qual Seeger (1981:212214) chama de sangere. Segundo ele, estes cantos são mais importantes e têm mais prestígio que as plantas medicinais. Através destes cantos, consegue-se influenciar as propriedades do corpo animal ou planta, transferindo ao paciente seus atributos para, assim , fortalecê-lo ou curá-lo.

21 A única exceção parece ser a utilização de um tipo de formiga como mei-kanê (mei = mel). Esta formiga, quando esmagada, tem o cheiro de mel. É utilizada como remédio para as picadas de marimbondos.

22 Entre os Piaroa, na Bacia do Orinoco, os cantos do xamã possuem também esta característica de cura (veja Overing 1990).

23 É importante assinalar que estes kanê são aplicados sobre o corpo da pessoa na forma de emplastro ou como embiras que são amarradas nos locais atacados. Sendo um remédio para garganta, amarra-se uma embira no pescoço; para um problema de estômago, amarra-se a embira no tórax, na altura daquele órgão.

24 Para uma análise suficientemente competente da morte entre os povos J ê-Timbira, ver Carneiro da Cunha (1978). Para Nimuendaju, são os amigos formais que ornamentam o defunto e cavam a sepultura ([1939] 1983:114). Mas ele não diz quem deve carregar o defunto até o cemitério. Carneiro da Cunha afirma que esta característica do funeral Apinaje, de qualquer pessoa retirar o defunto da casa, é uma outra "anomalia Apinaje". Muito embora minha intenção aqui não seja descrever o funeral Apinaje, os meus dados me informam que os amigos formais ornamentam o defunto e cavam a sepultura somente no caso de o falecido ser uma pessoa jovem que não tem genros, como no caso dos funerais que presenciei de uma criança e de um rapaz solteiro. Quando se trata de uma pessoa adulta, cujos filhos já se casaram, são os afins (sobretudo os genros) que cuidam da abertura da cova. No caso destes serviços funerários serem realizados por amigo formal, ele deverá ser recompensado por isso. Sendo um afim (genro) não se faz necessária tal recompensa. Não tenho informações precisas sobre quem retira o corpo da casa, mas creio que sejam mesmo outras pessoas não consangüíneas, juntamente com afins próximos (genros) e amigos formais.

25 Para min, os mẽ karõ vivem no mesmo espaço ocupado pelos vivos, mas num mundo invisível para a maioria, exceto para os wajaga.

26 Nimuendaju ([1939] 1983:108) também afirma que as almas dos mortos podem morrer, "transformando-se em animais, tocos de pau ou montículos de cupim".

27 É por esta interpretação dos Apinaje que eu acredito que venha sua predileção por carne gorda. Quando estão contando sobre uma caça que mataram, todos são unânimes em enfatizar que se trata de uma caça muito gorda. Para mim, é uma garantia de que não se tratava de um karõ incorporado. Certa vez, quando mataram uma vaca, que estava, aos olhos de um não-Apinaje, visivelmente magra, os homens que a esfolavam manifestaram grande satisfação quando encontraram um posta de gordura, exclamando: "eta!, mas está vaca tá gorda! (Môx Twym Tyx kumrë x)".

28 Esta informação está de acordo com as de Giannini (1991:147) sobre os Xikrin. Segundo ela, os Xikrin informam que o karõ se forma junto com o corpo da criança durante a relação sexual. Para ela, então, o karõ não é algo sobrenatural, mas um elemento do corpo. 


\section{REFERÊNCAS BIBUOGRÁFICAS}

BAMBERGER, J oan. 1967. Environment and Cultural Classification: A Study of the Northern Cayapó. PhD thesis, Cambridge, Massachusetts.

CARNEIRO DA CUNHA, Manuela. 1978. Os Mortos e os Outros: Uma Análise do Sistema Funerário e da Noção de Pessoa entre os Índios Krahó. São Paulo: Hucitec.

CASTELNAU, Francis. [1844] 1949. Expedições às Regiões Centrais da América do Sul. 2 vols. São Paulo: Editora Nacional.

DA_MATTA, Roberto A. 1976. Um Mundo Dividido: A Estrutura Social dos Índios Apinayé. Petrópolis: Vozes

DESCOLA, Philippe. [1986]1988. La Selva Culta. Simbolismo y Praxis en la Ecologia de los Achuar. Lima/ Quito: IFEA (Instituto Francés de Estudios Andinos)/Ed. Abya Yala.

GIANNINI, Isabelle Vidal. 1991. A Ave Resgatada: "A Impossibilidade da Leveza do Ser". Dissertação de mestrado, Universidade de São Paulo.

GIRALDIN, Odair. 2000. Axpên Pyràk. História, Cosmologia, Onomástica e Amizade Formal Apinaje. Tese de doutorado, IFCH - Unicamp.

LEA, Vanessa. 1986. Nomes e Nekrets Kayapó: Uma Concepção de Riqueza. Tese de doutorado, Museu Nacional - UFRJ .

MAYBURY-LEWIS, D. (ed.). 1979. Dialectical Societies. The Gê and Bororo of Central Brazil. Cambridge, Massachusetts: Harvard University Press.

NIMUENDAJ U, Curt. [1939] 1983. Os Apinayé. Belém: Museu Paraense Emílio Goeldi.

OVERING, J oana. 1990. “The Shaman as a Maker of Worlds: Nelson Goodman in the Amazon”. Man (N.S.) 25:602-619.

SEEGER, A. 1981. Nature and Society in Central Brazil: The Suyá Indians of Mato Grosso. Cambridge, Massachusetts: Harvard University Press.

. 1989. "Dualism: Fuzzy Thinking or Fuzzy Sets?". In: D. Maybury-Lewis \& Uri Almagor (eds.), The Attraction of Opposites: Thought and Society in the Dualistic Mode. Ann Arbor: University of Michigan Press.

TURNER, Terence S. 1979. "The Gê and Bororo Societies as Dialectical Systems: A general Model”. In: D. Maybury Lewis (ed.), Dialectical Societies. The Gê and Bororo of Central Brazil. Cambridge, Massachusetts: Harvard University Press.

VIVEIROS DE CASTRO, Eduardo. 1996. "Os pronomes cosmológicos e o perspectivismo ameríndio". Mana, 2(2): 115-144. 


\section{RESUMO}

Os povos J ê-falantes foram objeto de abordagens antropológicas que privilegiaram sobretudo as características sociológicas de sua organização social. Este artigo oferece - através de uma análise sobre as teorias apinaje sobre os espíritos (mẽ karõ), doença, cura, morte e vida post-mortem - uma interpretação da cosmologia apinaje que revela um mundo no qual os elementos estão unificados através da presença do espírito (o karõ).

\section{ABSTRACT}

The J ê-Speaking people have been object of anthropological approaches which have privileged above all sociological characteristics of their social organisations. This article offers through an analysis of apinaje theories about spirits, illness, healthiness, death and postmortem life - an interpretation of apinaje cosmology which reveals a world in which elements are unified through the presence of the spirit (the karõ). 